\title{
Şiddetli Osteoporozlu Hastalarda Teriparatid Tedavisi: Kemik Mineral Yoğunluğu, Biyokimyasal Parametreler, Sırt Ağrısı ve Yaşam Kalitesi Üzerine Etkiler
}

\author{
Teriparatide Treatment in Patients with Severe Osteoporosis: Effects on Bone Mineral \\ Density, Biochemical Parameters, Back Pain and Quality of Life
}

Alev Çevikol, Özgür Zeliha Karaahmet, Eda Gürçay, Gülşah Karataş, Ebru Karaca Umay, Aytül Çakcı

Dışkapı Yıldırım Beyazıt Eğitim ve Araştırma Hastanesi, Fizik Tedavi Kliniği, Ankara, Türkiye

\section{Özet}

Amaç: Şiddetli osteoporoz (OP) tablosu ve uzun süre bifosfonat kullanımı olan hastalarda Teriparatid (TPTD) tedavisinin kemik mineral yoğunluğu (KMY), biyokimyasal parametreler, sırt ağrısı ve yaşam kalitesi üzerine etkisinin değerlendirilmesi amaçlanmıştır.

Gereç ve Yöntem: Çalışmaya uzun süre bifosfonat tedavisi almış ancak cevap alınamamış şiddetli OP'si olan 15 hasta alındı. Hastalara 12 ay süre ile subkutan 20 mq/gün TPTD tedavisinin yanı sıra $800 \mathrm{IU} /$ gün D3 vitamini ve $1200 \mathrm{mg} /$ gün kalsiyum takviyesi verildi. Hastalar tedavi öncesi ve sonrası KMY, biyokimyasal parametreler, sırt ağrısı ve yaşam kalitesi bakımından değerlendirildi. Sırt ağrısı Vizüel Analog Skala (VAS), yaşam kalitesi Avrupa Osteoporoz Vakfı Yaşam Kalitesi Anketi (QUALEFFO) ile incelendi.

Bulgular: Çalışmaya alınan hastaların KMY, sırt ağrısı şiddeti ve yaşam kalitesi ölçeği QUALEFFO'nun sosyal fonksiyon alt grubu dışındaki tüm alt gruplarda tedavi öncesi ve sonrası değerler istatistiksel olarak anlamlı farklılık gösterirken biyokimyasal parametreler anlamlı düzeyde farklıık göstermedi.

Sonuç: TPTD tedavisi uzun süre bifosfonat kullanmış olan şiddetli OP'li hastaların tedavisinde iyi bir tedavi alternatifi olabilir. (Türk Osteoporoz Dergisi 2014;20: 51-5)

Anahtar kelimeler: Osteoporoz, teriparatid, sırt ağrısı, yaşam kalitesi

\section{Summary}

Objective: To evaluate effects of teriparatide therapy on bone mineral density (BMD), biochemical parameters, back pain, and quality of life in patients with severe osteoporosis, who had long-term bisphosphonate treatment.

Materials and Methods: Fifteen patients with severe osteoporosis who did not respond to bisphosphonate therapy after an extended period of treatment were enrolled in the study. Teriparatide therapy (20 $\mu \mathrm{q} /$ day) was administered subcutaneously for 12 months as well as 800 IU/ day of vitamin D3 and $1200 \mathrm{mg} /$ day of calcium. Patients were evaluated before and after teriparatide therapy in terms of BMD, biochemical parameters, back pain and quality of life. Back pain was assessed by Visual Analog Scale (VAS), and quality of life was assessed by the Quality of Life Questionnaire of the European Foundation for Osteoporosis (QUALEFFO).

Results: The BMD, VAS scale of back pain and all subgroups of QUALEFFO except the social function sub-group showed statistically significant differences before and after treatment. Biochemical parameters did not show any significant difference.

Conclusion: Teriparatide therapy may be a good alternative therapy in patients with severe osteoporosis in whom prolonged use of bisphosphonates was present. (Turkish Journal of Osteoporosis 2014;20: 51-5)

Key words: Osteoporosis, teriparatide, back pain, quality of life 


\section{Giriş}

Osteopororoz (OP), yüksek morbidite ve mortaliteyle ilişkili artmış kırık riskine neden olan, yaşlanan popülasyonun kronik bir hastalığıdır. Tedavide temel amaç, kemik kütlesini korumak ve OP'ye bağlı kırıkların oluşumunu önlemektir. OP tedavisinin etkinliği, ilacın potent olması ve ilaca uyum gösterilmesine bağlıdır $(1,2)$. Uzun süredir osteoklastik aktiviteyi azaltarak etki gösteren antirezorptif ilaçlar yaygın olarak kullanılırken yakın zamanda kemik yapımını arttıran ajanlar ağırlık kazanmaya başlamıştır. Özellikle paratiroid hormon (PTH) ilk öne çıkan ajan olmuştur. PTH'nin kemik üzerine etkisi karmaşıktır, uygulama şekline bağlı olarak kemik formasyonunu ve rezorbsiyonunu arttırabilir veya azaltabilir. Devamlı infüzyonlar serum PTH seviyesini sürekli yükselterek ciddi kemik rezorbsiyonuna ve kemik mineral yoğunluğunda (KMY) azalmaya neden olurken, günlük enjeksiyonlar serum PTH seviyesinde aralıklı yükselmeye, osteoblastik uyarılmaya ve KMY'de artışa, kortikal ve trabeküler yüzeylerde yeni kemik oluşumuna dolayısıyla kemik kütlesi ve gücünde artışa yol açar (3). Teriparatid (TPTD), rekombinantinsan PTH (1-34) peptidi olup, kırık için yüksek riskli olan veya daha önceki OP tedavilerine yanıt vermemiş olan ya da bunları tolere edemeyen idiyopatik veya hipogonadal OP'li erkekler ve postmenopozal kadınlar için FDA onayı almıştır. Önerilen kullanım şekli ve dozu 20 $\mu \mathrm{g} /$ gün subkutan enjeksiyon şeklindedir (4).

OP için risk faktörlerinin araştırılması ve Dual Enerji X-Ray Absorbsiyometri (DEXA) ile KMY'nin değerlendirilmesi oluşabilecek kırık riskini belirlemede hassas ve etkili olduğundan Dünya Sağlık Örgütü OP'yi DEXA ölçümüne göre tanımlamıştır. Ülkemizde de DEXA, OP tanı ve tedavi sonuçlarını değerlendirme konusunda altın standarttır $(5,6)$.

OP'nin klinik önemi vertebral veya non-vertebral kırık, sırt ağrısı, fonksiyonel kısıtılık, iyilik halinde azalma ve depresyona neden olarak yaşam kalitesini olumsuz etkileyebilmesidir $(7,8)$. Bu nedenle yaşam kalitesi ölçümleri bu hastaların değerlendirmesinde ve takibinde önemli bir rol oynamaktadır. $\mathrm{Bu}$ çalışmanın amacı şiddetli OP'si ve uzun süre bifosfonat kullanımı olan hastalarda TPTD tedavisinin KMY, biyokimyasal parametreler, sırt ağrısı ve yaşam kalitesi üzerine etkilerini değerlendirmektir.

\section{Gereç ve Yöntem}

Çalışmaya Eylül 2011-Ocak 2013 tarihleri arasında OP polikliniğinde takipte olan, şiddetli OP tanısı olan, daha önce uzun süre bifosfonat tedavisi almış ancak cevap alınamamış ve TPTD tedavisi uygulanmış olan 15 hasta başvurularına göre ardı sıra alındı. Illetişim kurmayı önleyecek düzeyde mental, işitsel ve görsel problemi, kemik ve kalsiyum metabolizmasını etkileyen OP dışında hastalığı (osteomalazi, Paget hastalığı, hipertiroidi, hiperparatiroidi, kronik böbrek ve karaciğer yetmezliği, malabsorbsiyon, malignensi) olan hastalar çalışmaya alınmadı. Hastaların dosyaları retrospektif olarak incelendi. Çalışma Helsinki Bildirgesine uygun olarak yürütüldü. Yaş, cinsiyet, OP tanı süresi, eşlik eden diğer hastalıklar, kullandığı ilaçlar, bifosfonat kullanım süresi, kırık hikayesi ve varsa yeri, kifoplasti varlığı, KMY, biyokimyasal parametreler ve sırt ağrısı bilgileri kaydedildi. Laboratuvar parametrelerde; kalsiyum: 8,1-10,7 mg/ dl, fosfor: 2,3-4,7 mg/dl, alkalen fosfataz: $95-280 \mathrm{U} / \mathrm{L}$, üre: 5-24 $\mathrm{mg} / \mathrm{dl}$, kreatinin: 0,4-1,4 mg/dl, 25-OH vitamin D3: 30-80 $\mathrm{\mu g} / \mathrm{L}$ ve PTH: 9-78 pq/ml değerleri (Dışkapı Yıldırım Beyazıt Eğitim ve Araştırma Hastanesi Biyokimya Laboratuvarı tarafından belirlenmiş olan normal aralıklar) normal olarak not edildi (9). Lomber vertebralardan (L1-L4 arası anterior pozisyonda) ve proksimal femurdan DEXA cihazı (Hologic) ile yapılan $\mathrm{KMY}$ sonuçları $\mathrm{gr} / \mathrm{cm}^{2}$ olarak ve pik genç erişkin kemik yoğunluk değerine göre belirlenen T skorları ile değerlendirildi. Dorsolomber, lateral grafileriile incelenen vertebral yükseklik kayıpları kaydedildi.

Yerleşmiş OP tanısı Dünya sağlık örgütü sınıflanmasına göre (T skoru $<-2,5$ ve $\geq 1$ fazla kırık) tanımlandı (5). Bir vertebranın üç yükseklik ölçümünden en az biri en yakın normal vertebranın yükseklik ölçümünden \%20 azalmış ise bu kırık olarak kabul edildi (10).

Sırt ağrısı şiddeti 0-100 mm'lik Vizuel Analog Skala (VAS) ile değerlendirildi, "0" ağrının olmadığını, "100" şiddetli ağrı olduğunu göstermekteydi.

Yaşam kalitesi Türkçe geçerlilik ve güvenirliliği olan ve OP'ye spesifik olan Avrupa Osteoporoz Vakfı Yaşam Kalitesi Anketi (QUALEFFO) ölçeği ile değerlendirildi. Bu ölçek ağrı, fiziksel fonksiyon, sosyal fonksiyon, genel sağlık değerlendirmesi ve mental fonksiyon olmak üzere 5 alt gruptan oluşmakta ve toplam 41 soru içermektedir. QUALEFFO total ve alt ölçekler bazında 0-100 arası skorlanmakta ve yüksek skorlar düşük yaşam kalitesini göstermektedir (11).

Tüm hastalar 12-18 ay süre ile subkutan $20 \mu \mathrm{g} / \mathrm{gün}$ TPTD, ek olarak $800 \mathrm{IU} /$ gün D3 vitamini ve 1200 mg/gün kalsiyum tedavisi aldı. Hastaların dosya bilgilerinden tedavi öncesi (TÖ) ve tedavinin 12. ayında (TS) değerlendirilen KMY, biyokimyasal parametreleri, sırt ağrısı ve yaşam kalitesi düzeyleri kaydedildi. Verilerin analizi SPSS for Windows 20 paket programında yapıldı. Tanımlayıcı istatistikler Chi-kare testleri kullanılarak ortalama \pm standart sapma ve gözlem sayısı (\%) şeklinde gösterildi. Gruplar içinde değişkenler yönünden farkın önemliliği Wilcoxon Testi ile değerlendirildi, $p<0,05$ için sonuçlar istatistiksel olarak anlamlı kabul edildi.

\section{Bulgular}

Çalışmaya alınan 15 hastanın demografik ve klinik özellikleri Tablo 1'de ve KMY değerleri, biyokimyasal parametreleri, sırt ağrısı şiddeti ve QUALEFFO ölçeğinin bazal değerleri Tablo 2'de sunuldu. Hastaların TPTD tedavisine katılımlarının akış şeması Şekil 1'de gösterildi. Tedavinin 12 ayını tamamlayamayan 5 hastadan biri 2. ayında, biri 4. ayında yan etki nedeniyle, ikisi 6. ayında maddi yetersizlik, etkisizlik ve yan etki nedeniyle, biri 8. ayında exitus olması nedeniyle tedaviyi bıraktı. Hastalar yan etki olarak tolere edilemeyen halsizlik, baş dönmesi ve bulantı tarif ettiler. Kaybedilen hasta ölüm nedeni uzun süredir 
romatoid artrit nedeniyle kullanılan steroide bağlı gelişen femur fraktürünün komplikasyonu idi. Hastaların KMY, biyokimyasal parametreler, sırt ağrısı şiddeti ve QUALEFFO değerlerinin TÖ ve TS karşılaştırması Tablo 3'de sunuldu.

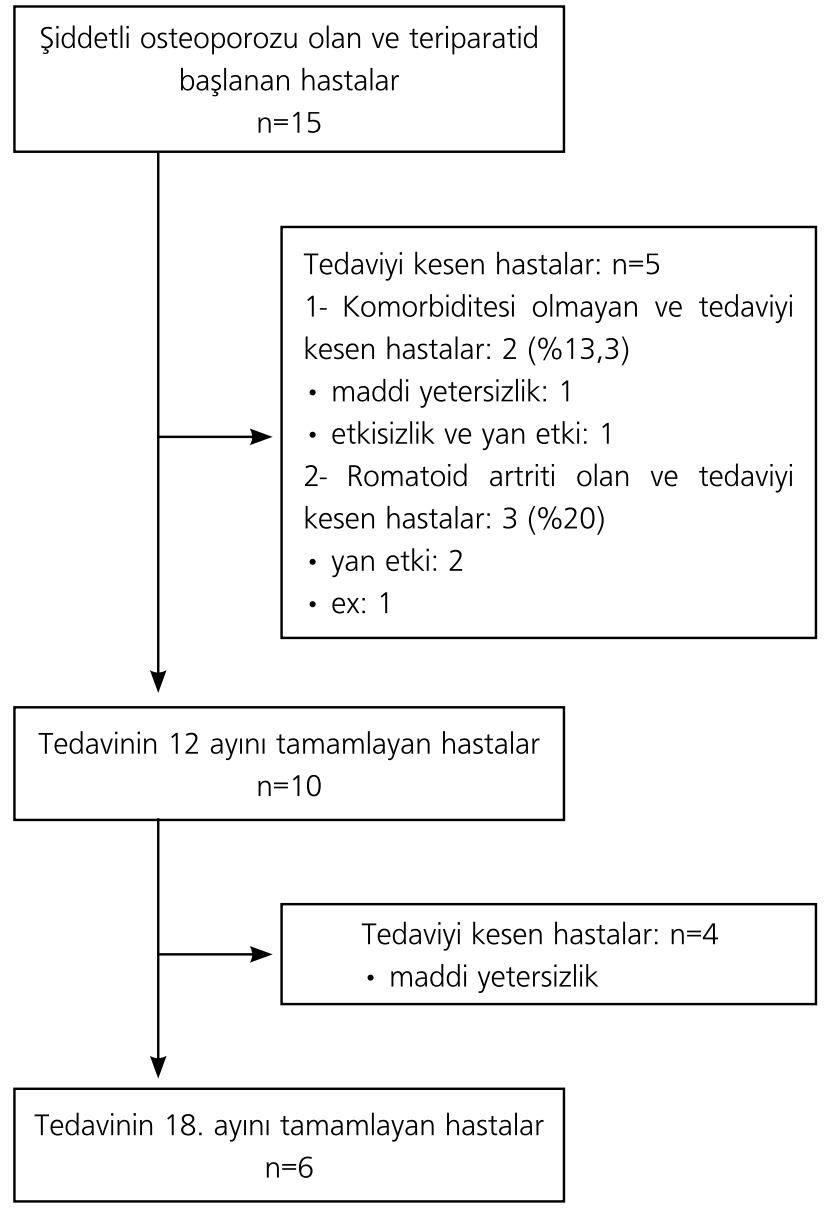

Şekil 1. Hastaların TPTD tedavi sürecine katııımlarının akış şeması

\begin{tabular}{|l|l|}
\hline \multicolumn{2}{|l|}{ Tablo 1. Hastaların demografik ve klinik özellikleri } \\
\hline Değişkenler & $\begin{array}{l}\text { n=15 } \\
\text { Ort } \pm \text { SS veya } \mathbf{n}(\%)\end{array}$ \\
\hline Yaş (yıl) & $72,8 \pm 7,8$ \\
\hline Cinsiyet & $12(80)$ \\
\hline Kadın & $3(20)$ \\
\hline Erkek & $10,2 \pm 4,9$ \\
\hline Osteoporoz süresi (yıl) & $7,4 \pm 2,2$ \\
\hline Bifosfonat süresi (yıl) & $2,8 \pm 0,9$ \\
\hline Vertebral kırık sayısı & \multicolumn{2}{|l|}{} \\
\hline Nonvertebral kırık & $2(13,3)$ \\
\hline Kalça & $1(6,7)$ \\
\hline Kolles & $2(13,3)$ \\
\hline Kifoplasti & \multicolumn{2}{|l}{} \\
\hline OrtıSS: ortalama \pm standart sapma &
\end{tabular}

\section{Tartışma}

Çalışmamızda, ortalama 7,4 yıl bifosfonat tedavisi almış, şiddetli OP tanılı hastalarda TPTD tedavisinin bir yıl sonundaki etkisi incelendi. Sonuçta KMY değerleri, sırt ağrısı şiddeti ve yaşam kalitesi ölçeğinin sosyal fonksiyon alt grubu dışındaki tüm

\begin{tabular}{|c|c|}
\hline Değişkenler & Ort \pm SS \\
\hline Lomber (L1-L4) t-skor & $3,9 \pm 1,1$ \\
\hline Femur total t-skor & $3,6 \pm 0,6$ \\
\hline Sırt ağrısı (VAS) & $82 \pm 17$ \\
\hline \multicolumn{2}{|l|}{ QUALEFFO } \\
\hline Ağrı & $76,3 \pm 22$ \\
\hline Fiziksel Fonksiyon & $71,2 \pm 21$ \\
\hline Sosyal Fonksiyon & $78,9 \pm 15$ \\
\hline Genel Sağlık & $76,6 \pm 18$ \\
\hline Mental Fonksiyon & $62,7 \pm 27$ \\
\hline Toplam skor & $67,6 \pm 17$ \\
\hline \multicolumn{2}{|c|}{$\begin{array}{l}\text { Ort } \pm \text { SS: ortalama } \pm \text { standart sapma, KMY: kemik mineral yoğunluğu, } \\
\text { VAS: Vizüel Analog Skala, QUALEFFO: Avrupa Osteoporoz Vakfı Yaşam Kalitesi } \\
\text { Anketi }\end{array}$} \\
\hline
\end{tabular}

\section{Tablo 3. Hastaların tedavi öncesi ve sonrası KMY, biyokimyasal parametreler, sırt ağrısı şiddeti ve QUALEFFO değerlerinin karşılaştırılması}

\begin{tabular}{|c|c|c|c|}
\hline Değişkenler & $\begin{array}{l}\text { TÖ } \\
\text { Ort } \pm \text { SS }\end{array}$ & $\begin{array}{l}\text { TS } \\
\text { Ort } \pm \text { SS }\end{array}$ & $\mathbf{p}$ \\
\hline Lomber (L1-L4) t skor & $3,8 \pm 1,2$ & $2,7 \pm 1,3$ & 0,005 \\
\hline Femur total t skor & $3,7 \pm 0,5$ & $3,4 \pm 0,7$ & 0,028 \\
\hline \multicolumn{4}{|c|}{ Biyokimyasal parametreler } \\
\hline Kalsiyum & $9,2 \pm 0,5$ & $9,3 \pm 0,4$ & 0,151 \\
\hline Fosfor & $3,8 \pm 0,5$ & $3,5 \pm 0,5$ & 0,06 \\
\hline Alkalen fosfataz & $95,9 \pm 38$ & $107,3 \pm 41$ & 0,114 \\
\hline Paratiroid hormon & $46 \pm 26$ & $47 \pm 26$ & 0,202 \\
\hline 25-OH Dvitamini & $25 \pm 10$ & $21 \pm 5,8$ & 0,283 \\
\hline Üre & $41,3 \pm 8,1$ & $42,6 \pm 8,6$ & 0,259 \\
\hline Kreatinin & $0,8 \pm 0,1$ & $0,8 \pm 0,1$ & 0,102 \\
\hline Sırt ağrısı (VAS) & $78 \pm 19$ & $19 \pm 17$ & 0,005 \\
\hline \multicolumn{4}{|l|}{ QUALEFFO } \\
\hline Ağrı & $69 \pm 23$ & $20 \pm 16$ & 0,005 \\
\hline Fiziksel Fonksiyon & $71 \pm 23$ & $52 \pm 27$ & 0,033 \\
\hline Sosyal Fonkisyon & $82 \pm 12$ & $76 \pm 12$ & 0,068 \\
\hline Genel Sağlık & $77 \pm 18$ & $50 \pm 26$ & 0,007 \\
\hline Mental Fonksiyon & $60 \pm 27$ & $31 \pm 33$ & 0,012 \\
\hline Toplam skor & $67,9 \pm 18$ & $48,5 \pm 22$ & 0,009 \\
\hline \multicolumn{4}{|c|}{$\begin{array}{l}\text { Ort } \pm \text { SS: ortalama } \pm \text { standart sapma, KMY: kemik mineral yoğunluğ } \\
\text { VAS: Vizüel Analog Skala, QUALEFFO: Avrupa Osteoporoz Vakfı Yaşam Kalite } \\
\text { Anketi }\end{array}$} \\
\hline
\end{tabular}


parametrelerde anlamlı düzeyde iyileşme olduğu belirlenirken biyokimyasal parametreler açısından önemli bir değişiklik olmadığı gözlendi.

Bifosfonatlar OP tedavisinin temel ilaçlarıdır. Uzun dönem kullanımları ile atipik femur fraktürünün ilişkili olduğunun gösterilmesi üzerine 2010 yılında FDA uzamış bifosfonat kullanımına bağlı gelişen kırıklarda artmış riske dikkat çekmek için bifosfonatların değiştirilmesini tavsiye etmiştir (6). Son yıllarda antirezorptif ajan olan bifosfonatları uzun süre kullanan hastalarda, anabolikajan olan TPTD tedavisinin kullanımı gündeme gelmiştir. TPTD, şiddetli OP'li erkek, postmenapozal kadın ve glukokortikoide bağlı OP'si bulunan hastaların tedavisinde kabul edilmektedir. Ayrıca 65 yaş altındaki yüksek kırık riskine sahip çok düşük $K M Y^{\prime} l i$ kişilerde de tedavide göz önünde bulundurulması önerilmiştir (12). Ancak ülkemizde OP tedavisinde TPTD kullanımı henüz oldukça sınılı olup, yan etkileri, tedavi sonuçları konusunda yeterli klinik tecrübe ve çalışma bulunmamaktadır.

TPTD tedavisinin 138 hasta ile değerlendirildiği bir çalışmada, vertebral ve femoral KMY'de tedavi sonrası anlamlı artış olduğu belirlenmiş, benzer sonuçlar Keaveny ve ark.'nın yapmış olduğu orijinal faz 3 çalışmasında da gösterilmiştir $(13,14)$. Çalışmamızda tedavi sonrası vertebral ve femoral KMY değerlerinde anlamlı artış saptanmış, TPTD'nin trabekülanın kalınlığını arttırarak KMY'yi arttırdığı bilgisiyle uyumlu sonuçlar elde edilmiştir.

Hodsman ve ark. (12) TPTD tedavisi sonrası kemik yapım ve yıkımını gösteren biyomarkerların artışını ilk olarak dökümente etmiş, daha sonra bu durum birçok çalışmada yer almıştır $(15,16)$. Neer ve Orwoll'un çalışmasında serum $25-\mathrm{OH}$ vitamin D3 ve kalsitriol düzeylerinde tedavi öncesi değerlere göre artış olduğu, serum kreatinin konsantrasyonunda değişme olmadığı, serum Ca ve ürik asit düzeylerinin bir miktar yüksek seyretse de üst sınırı aşmadığı rapor edilmiştir $(3,17)$. Bizim çalışmamızda TPTD tedavisi sonrası biyokimyasal parametreler farklıık göstermemiştir. Tedavi öncesi ve sonrası düzeyleri normal sınırlarda iken sadece 25-OH vitamin D3 düzeylerinin normal sınırların altında olduğu gözlenmiştir.

TPTD tedavisinin sırt ağrısını azalttığını belirlediğimiz çalışmamıza benzer şekilde postmenopozal OP'li kadınlarda teriparatid tedavisi ile vertebra fraktürüne bağlı orta veya şiddetli sırt ağrısı insidansının azaldığı gösterilmiştir (10). Rajzbaum ve ark. (18) TPTD’yi değerlendirdiği çok merkezli The European Forsteo Observational Study (EFOS) çalışmada, klinik kırık görülme sıklığı, sırt ağrısı ve yaşam kalitesi parametrelerini incelemiş, toplam 309 hastanın dahil edildiği çalışmada klinik kırık görülme sıklığının, özellikle vertebralarda, tedavi sonrası 6. ayda azalmaya başladığını ve 36. ayda devam ettiğini, sırt ağrısı ve yaşam kalitesine etkinin 18. ve 36. aylarda belirgin gelişme gösterdiğini raporlamıştır.

Çalışmaya dahil ettiğimiz hastaların ikisinin öyküsünde kifoplasti cerrahisi vardı. Vertebra kırığı olan hastalarda, 2-3 hafta iyi bir analjezi programına rağmen devam eden ağrı varsa, yapılan vertebroplasti veya kifoplasti ağrıda kısa süreli azalma sağlayabilir. Ancak özellikle akut ağrıı dönemde uygulanan bu işlemin yapıldığı segmentin bir alt ve üst seviyelerinde basınç artışına bağlı yeni vertebra kırığı gelişebileceği için cerrahi tedavi seçeneği cerrahinin riskleri ve hastanın yakınmaları ile birlikte bir bütün halinde değerlendirilerek uygulanmalıdır $(19,20)$.

Dünyada önemli bir sağlık sorunu olan OP yarattığı ağrı, fiziksel kısıtlılık ve iyilik halinde bozulma nedeniyle yaşam kalitesini olumsuz yönde etkiler. OP'li hastalarda klinik olarak tedavi stratejilerini belirleme ve tedavi etkinliğini değerlendirme bakımından yaşam kalitesinin değerlendirilmesi önemli yer tutmaktadır (8). Vertebral kırık varlığının, sayısının ve şiddetinin düşük yaşam kalitesi ile ilişkili olduğu bildirilmiştir $(21,22)$. MORE çalışması kapsamında, Avrupa ülkelerinde postmenopozal OP'si olan kadınların yaşam kalitesine vertebral kırıkların etkisi incenmiş, vertebral kırığı olanlarda yaşam kalitesinin daha düşük olduğu bildirilmiştir (23). Nur ve ark. (24) vertebral kırı̆ı̆ bulunan osteoporotik kadınların yaşam kalitesinin vertebral kırığı olmayan osteoporotik ve osteopenik kadınlardan anlamlı düzeyde düşük olduğunu belirlemiştir. Akyol ve ark. (25) şiddetli postmenopozal OP'si olan 13 hastada TPTD tedavisinin sırt ağrısı, yaşam kalitesi, depresyon ve biyokimyasal parametreler üzerine etkisini incelemiş, 6 ay sonra sırt ağrısı, yaşam kalitesi ağrı alt parametresi ve total yaşam kalitesi skoru açısından iyileşme saptarken, depresyon düzeyi ve biyokimya parametreler açısından anlamlı fark bulamamıştır. Langdahl ve ark. (26) tarafından yapılan çok merkezli EFOS çalışmasında 1648 postmenopozal OP'li hastada 18 ay süre ile uygulanan TPTD tedavisinin etkinliği araştırılmış, yaşam kalitesi ve ağrı düzeylerinde 3. ayda başlamak üzere, yapılan tüm kontrollerde belirgin iyileşme olduğu saptanırken, frajilite kıı̆ı̆ı insidansının ilk 6 aydan itibaren giderek azaldığı kaydedilmiştir. Yaşam kalitesindeki düzelmenin özellikle günlük aktivite ve ağrı alt parametrelerinde olduğu bildirilmiştir. Retrospektif bir çalışmada, yaş ortalaması 63,8 yıl olan 57 OP hastasında TPTD tedavisi Mini Osteoporoz Yaşam Kalitesi Anketi (OQLQ) ile değerlendirilmiştir. Semptom, emosyonel fonksiyon ve boş zaman aktivitelerinde 3. ayda, günlük yaşam aktivitelerinde ise 6. ayda iyileşme saptanır iken, fiziksel fonksiyonlarda her iki kontrolde de anlamlı iyileşme olmadığı görülmüştür (27). Çalışmamızdaki tüm hastaların şiddetli OP tanısı kapsamında vertebral kırıkları bulunurken ortalama vertebral kırık sayısı 2,8 olarak not edilmiştir. Araştırmamızda sadece vertebral kıı̆̆ı olan hastalarda TPTD'nin etkileri değerlendirilmiş, yaşam kalitesinin sosyal fonksiyon alt grubu dışındaki tüm alt gruplarda iyileşme sağladığı belirlenmiştir.

TPTD tedavisi alan hastaların \%1-\%3'ünde hiperkalsemi, hiperürisemi, baş dönmesi, başağrısı, bulantı, bacak krampları gibi yan etkiler gelişebilir $(3,28,29)$. Çok merkezli gözlemsel bir çalışmada 18 ay süreyle tedaviye devamlılık oldukça yüksek oranda $(\% 86,85)$ bulunmuş, baş ağrısı, baş dönmesi, artralji, depresyon ve hipertansiyon en sık görülen yan etkiler olarak not edilmiştir (1). EFOS çalışmasının 6. ay kontrolünde çalışmadan ayrılma oranı \%12,3 olarak bulunurken, ayrıma nedenleri ilaç yan etkileri, hasta kararı ve hekim kararı olarak belirtilmiştir (26). Tedavi esnasında en sık görülen yan etkiler bulantı, baş ağrısı, yorgunluk ve depresyon şeklinde raporlanmıştır. McNeilly ve 
ark. 138 hastanın 60'ının 18. ayı tamamlayabildiği, 15 hastanın yan etki nedeniyle tedaviyi bıraktığını kaydetmiştir (30). Bizim çalışmamızda TPTD tedavisini 18. aya kadar kullananların oranı \%40 iken yan etki nedeniyle tedaviyi bırakanların oranı (\%20) oldukça düşük bulunmuş, özellikle RA hastalarının tedaviyi bırakmaları, çoklu ilaç kullanımının etkili bir neden olabileceğini düşündürmüştür. Yan etki olarak şiddetli halsizlik, baş dönmesi ve bulantı not edilirken, tedaviye devam edememenin en önemli nedeni olarak maddi yetersizlik dikkati çekmiştir.

Çalışmamızın kısıtılıkları hasta sayısının az olması, hastaların genel poliklinik yerine OP polikliniğine başvuran hastalardan seçilmiş olması ve değerlendirmenin prospektif yapılmamasıdır. Ancak ülkemizde az sayıdaki araştırmalardan biri olan bu çalışmada, tüm hastaların vertebral kırı̆̆ı olması homojen bir dağılım sağlarken, laboratuvar parametrelerin yanı sıra klinik sonuçların da değerlendirilmesi klinisyenlere yapacakları çalışmalarda yol göstermesi bakımından önemlidir.

\section{Sonuç}

KMY skorları, sırt ağrısı, yaşam kalitesi parametreleri TPTD tedavisiyle önemli oranda düzelme gösterdiğinden uzun süre bifosfonat kullanmış olan şiddetli OP'li hastaların tedavisinde TPTD iyi bir tedavi alternatifi olabilir. Ülkemizde TPTD tedavisinin etkileri ile ilgili verilerin daha iyi ortaya konabilmesi ve problemlerin anlaşılabilmesi için çok daha fazla sayıdaki hasta gruplarılla yapılacak çok merkezli prospektif çalışmalara ihtiyaç olduğu kanaatindeyiz.

\section{Kaynaklar}

1. Migliaccio S, Resmini G, Buffa A, Fornari R, Di Pietro G, Cerocchi I, et al. Evaluation of persistenceandadherenceto teriparatide treatment in patientsaffectedby severe osteoporosis (PATT): a multicenter observationalreal life study. Clin Cases Miner Bone Metab 2013;10:56-60.

2. Silverman SL, Gold DT, Cramer JA. Reducedf racture rates observe donlyin patients with properpersistence and compliance with bisphosphonate therapies. South Med J 2007;100:1214-8.

3. Neer RM, Arnaud CD, Zanchetta JR, Prince R, Gaich GA, Reginster JY, et al. Effect of parathyroidhormone (1-34) on fracturesand bone mineral density in postmenopausal women with osteoporosis. N Engl J Med 2001;344:1434-41.

4. Bodenner D, Redman C, Riggs A. Teriparatide in themanagement of osteoporosis. Clin Interv Aging 2007;2:499-507.

5. The WHO Study Group. Assessment of fracture risk and its application to screening for postmenopausal osteoporosis. Geneva. World Health Organ Tech Rep Ser. 1994;843:1-129.

6. Das S, Crockett JC. Osteoporosis-a currentview of pharmacological prevention and treatment. Drug Des Devel Ther 2013;7:435-48.

7. Lips $P$, vanSchoor NM. Quality of life in patients with osteoporosis. Osteoporos Int 2005;16:447-55.

8. Yılmaz H, Erkin $G$, Demir-Polat $H A$, Küçükşen $S$, Sallı $A$, Uğurlu H. Osteoporozda Yaşam Kalitesi: Bir Kontrollü Çalışma. Türk Osteoporoz Dergisi 2012;18:47-52.

9. Giniş Z. Biyokimya Laboratuvarı Test Rehberi. 2013 01(4) Available from:s URL:http://www/diskapieah.gov.tr/ diskapi/ dokumanlar/test-guvenlik-rehberi/BiY-RH-02-BiYOKiMYA-LAB.TEST-REHBERi.

10. Genant HK, Wu CY, van Kuijk C, Nevitt MC. Vertebral fracture assessment using a semi quantitative technique. J Bone Miner Res 1993;8:1137-48.

11. Koçyiğit H, Gülseren $S$, Erol A, Hizli N, Memis A. The reliability and validity of the Turkish version of quality of life questionnaire of th eeuropean foundation for osteoporosis (QUALEFFO). Clin Rheumatol 2003;22:18-23.
12. Hodsman AB, Bauer DC, Dempster DW, Dian L, Hanley DA, Harris ST, et al. Parathyroid Hormoneand Teriparatide for the Treatment of Osteoporosis: A Review of the Evidence and Suggested Guidelines for Its Use. Endocr Rev 2005;26:688-703.

13. McNeilly T, McNally C, Finch M, Beringer T. Recombinant PTH: a study of theoutcome of teriparatidetherapyfor 138 patients with osteoporosis. Ulster Med J 2013;82:89-93.

14. Keaveny TM, Donley DW, Hoffmann PF, Mitlak BH, Glass EV, San Martin JA. The effects of teriparatide and alendronate on vertebral strength as assessed by finite element modeling of QCT scans in women with osteoporosis. J Bone MinRes 2007;22:14957.

15. Kurland ES, Cosman F, McMahon DJ, Rosen CJ, Lindsay R, Bilezikian JP. Parathyroid hormone as a therapy for idiopathic osteoporosis in men: effects on bone mineral densityand bonemarkers. J Clin Endocrinol Metab 2000;85:3069-76.

16. Body JJ, Gaich GA, Scheele WH, Kulkarni PM, Miller PD, PeretzA, et al. A randomized double-blind trial to compare the efficacy of teriparatide [recombinant human parathyroid hormone (1-34)] with alendronate in postmenopausal women with osteoporosis. J Clin Endocrinol Metab 2002:87:4528-35.

17. Orwoll ES, Scheele WH, Paul S, Adami S, Syversen U, Diez-Perez $A$, et al. The effect of teriparatide [human parathyroid hormone (1-34)] therapy on bone density in men with osteoporosis. J Bone Miner Res 2003;18:9-17.

18. Rajzbaum G, Grados F, Evans D, Liu-Leage S, Petto H, AugendreFerrante $B$. Treatment persistence and changes in fracture risk, backpain, andquality of life amongst patients treated with teriparatide in routine clinicalcare in France: Results from the European Forsteo Observational Study. Joint Bone Spine 2013;81:69-75.

19. Sindel D. Günümüzde ve Gelecekte osteoporoz tedavisi. Türk Fiz Tıp Rehab Derg 2013;59:330-7

20. Lamy O, Uebelhart B, Aubry-Rozier B. Risks and benefits of percutaneous vertebroplasty or kyphoplasty in the management of osteoporotic vertebral fractures. Osteoporos Int 2014;25:80719.

21. Sanfelix-Genoves J, Hurtado I, Sanfelix-Gimeno G, Reig-Molla B, Peiro S. Impact of osteoporosis and vertebral fractures on qualityof-life. A population-basedstudy in Valencia, Spain (The FRAVO Study). Health Qual Life Outcomes 2011:6;9:20.

22. Fechtenbaum J, Cropet C, Kolta S, Horlait S, Orcel P, Roux C. Theseverity of vertebral fractures and health-related quality of life in osteoporotic post menopausal women. Osteoporos Int 2005;16:2175-9.

23. Oleksik A, Lips P, Dawson A, Minshall ME, Shen W, Cooper C, et al. Health related quality of life in postmenopausal women with low BMD with or without prevalent vertebral fractures. J Bone Miner Res 2000;15:1384-92.

24. Nur H, N. Toraman F. Postmenopozal Osteoporozda Vertebral Kırıkların Yaşam Kalitesine Etkisi. Türk Osteoporoz Dergisi 2011;17:81-4

25. Akyol Y, Atmaca A, Durmuş D, Ulus Y, Tander B, Alaylı G. Şiddetli Postmenopozal Osteoporozlu Hastalarda Teriparatid Tedavisinin Ağrı, Yaşam Kalitesi, Depresyon ve Biyokimyasal Parametreler Üzerine Etkisi: Erken Dönem Sonuçlar. Turk Fiz Tıp Rehab Derg 2011;:57:134-8.

26. Langdahl BL, Gerald R, Jakop F, Karras D, Ljunggren O, Lems WF, et al. Calcif Tissue Int 2009;85:484-93.

27. Nau AN, Ali SH, Sawka AM, Thabane L, Papaioannou A, Gafni A, et al. Improvement in health-relatedquality of life in osteoporosis patients treated with teriparatide. BMC Musculoskelet Disord 2008;9:151.

28. Gold DT, Patnos BS, Masica DN, Misurski DA, Marcus R. Initial experience with teriparatide in the United States. Curr Med Res Opin 2006;22:703-8.

29. Canalis E, Giustina A, Bilezikian JP. Mechanism of anabolic therapies for osteoporosis. N Engl J Med 2007;357:905-16.

30. McNeilly $T$, McNally C, Finch M, Beringer T. Recombinant PTH: a study of the outcome of teriparatide therapy for 138 patients with osteoporosis. Ulster Med J 2013;8:89-93. 